\title{
Reseña del libro La desmodernidad mexicana y las alternativas a la violencia y a la exclusión en nuestros días
}

\author{
Jorge Regalado
}

SERGIO ZERMEÑO, 2005

La desmodernidad mexicana y las alternativas a la violencia y a la exclusión en nuestros días

Océano, México.

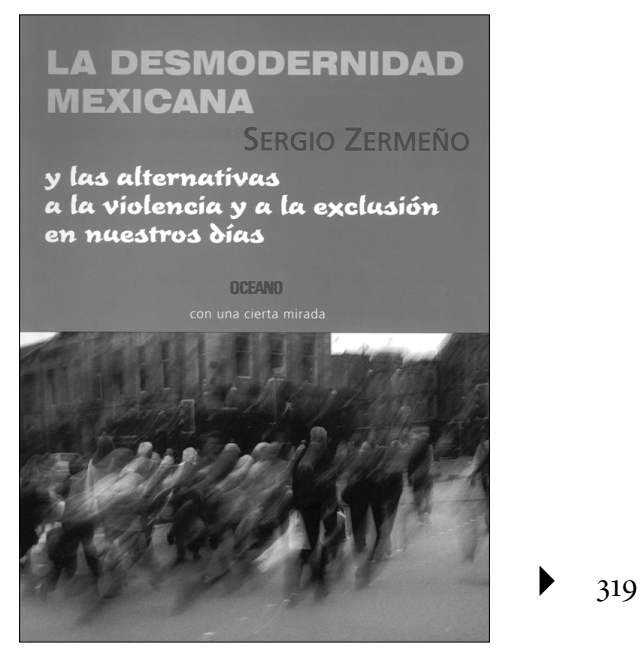

$\mathrm{E}$ ste nuevo libro de Sergio Zermeño aparece en un momento muy oportuno, justo cuando muchos intelectuales están haciendo esfuerzos especiales de producción y generación de ideas. Estamos viviendo tiempos de imaginación política, quizá como los vividos en 1968 y en 1988 con la emergencia del neocardenismo. El país está inmerso en una serie de procesos sociopolíticos de lo más interesante a propósito de dos procesos que involuntariamente han coincidido en el calendario político: las precampañas electorales por la disputa de candidaturas al interior de cada partido, y La otra campaña a la

JORGE REGALADO: Centro Universitario de Ciencias Sociales y Humanidades, Universidad de Guadalajara, Guadalajara, México. rsj39838@gmail.com

Desacatos, núm. 23, enero-abril 2007, pp. 319-324. que está convocando el Ejército Zapatista de Liberación Nacional (EZLN) a partir de la Sexta Declaración de la Selva Lacandona. En el debate suscitado por esta nueva iniciativa zapatista, Sergio Zermeño ha participado con varias opiniones, planteando interrogantes muy sugerentes a la propuesta y el llamado zapatista.

Este libro sirve de manera excelente para fortalecer la idea de que sí existen alternativas frente a la situación que estamos viviendo los mexicanos y que es falso que el conservadurismo sea el pensamiento único. Hay una continuidad con el anterior, La sociedad derrotada. El desorden mexicano de fin de siglo ${ }^{1}$. Celebro a la vez la diferencia que se nota desde el título, en el tono y sentido de las palabras. Sergio ha superado —él mismo lo reconoce-

\footnotetext{
${ }^{1}$ Siglo XXI, México, 1996.
} 
su etapa pesimista de la sociedad derrotada y ahora, con optimismo y esperanza, presenta una posición desde la cual apuesta a la búsqueda de alternativas al capitalismo en la etapa de la globalización, particularizando en el contexto general mexicano que él denomina como de desorden social y desmodernidad de nuestro sistema político. Esto me lleva a recordar que hace varios años, cuando el pensamiento conservador era apabullante, don Pablo González Casanova insistía en crear un programa de estudios que se llamará "Las alternativas".

El presente es un texto integrado por seis capítulos y las conclusiones, se lee rápido y su mensaje es comprensible. Aunque el caso particular que presenta se refiere a los comités vecinales y a la Ley de Participación Ciudadana del Distrito Federal, sus reflexiones no parten del típico centralismo que pretende generalizaciones a partir de los sucesos acontecidos en la capital del país. En el anexo se alude a 54 experiencias organizativas de 17 entidades del país ${ }^{2}$. Desde luego que la condensación social - término con el que Sergio se refiere a la sociedad civil organizada y en lucha - no se agota en estos casos y seguramente se puede ampliar a las 31 entidades del país. El número, afortunadamente, es mucho mayor, pero hace falta una actualización del mapa nacional del tejido social organizado. Valga como ejemplo decir que hasta antes del 3 de septiembre de 2005 habían viajado, desde diferentes partes del país, hasta algunas poblaciones chiapanecas para participar en las reuniones con el EZLN representantes de 95 organizaciones indígenas, 143 organizaciones sociales, 392 organizaciones no gubernamentales, colectivos y grupos diversos, además de 51 organizaciones políticas ${ }^{3}$.

El objetivo central que Sergio persigue con este texto es demostrar "por qué en nuestro país se ha gestado una forma de organización sociopolítica que ha fortalecido primordialmente al Estado y no a la sociedad". La hipótesis del predominio de esta tendencia histórica Estadocéntrica no es nueva, pero lo novedoso y el aporte de Ser-

2 Aguascalientes, Baja California, Campeche, Chiapas, Chihuahua, Coahuila, Guanajuato, Guerrero, Hidalgo, Jalisco, Michoacán, Oaxaca, Puebla, Querétaro, Tabasco, Veracruz y Yucatán.

${ }^{3}$ Véase $<$ www.fzln.org.mx $>$. gio, me parece, se encuentran justamente en que da pistas para entender las razones del desarrollo histórico de dicha tendencia, así como los esfuerzos teóricos y de elaboración conceptual que se han construido en Europa y América Latina para justificar y mantener dicha tendencia en sus diversos momentos históricos, así como para ponerla en cuestión.

El autor nos muestra una imagen de la situación del país desde que tenemos una economía abierta, definiendo a ésta como el enemigo de nuestro tiempo. Puras malas noticias y lo peor es que todas están bien sustentadas: el deterioro ambiental, la crisis del campo y los campesinos y el avance de la Coca Cola y McDonalds; la pobreza y el hambre que ya cubre un amplio territorio del México urbano y rural; la destrucción de empresas y empleos; la descomposición social, con la utilización de los casos de los cientos de mujeres asesinadas en Ciudad Juárez y la violencia e inseguridad que asola a toda el país. Hace también una revisión de la situación de varias industrias micro, pequeñas, medianas y grandes; del empleo informal y marca el hecho de la pérdida del valor positivo que tenía el trabajo. En el medio delictivo, nos cuenta Sergio, estar atracando ahora se dice "estoy trabajando". Se comprueba que nuestra economía está basada en cuatro pilares: el petróleo, la maquila, las remesas de los migrantes y el narcotráfico. Con estos datos uno se puede preguntar: ¿qué tan viable es nuestro país?

Cuando alude al caso de Ciudad Juárez, llama la atención la hipótesis del machismo ultrajado. Dice Sergio: “[...] esas mujeres jóvenes de Ciudad Juárez y de toda la frontera norte son las que tienen un empleo, las que tienen la disciplina y la resignación para trabajar por ese salario, con rutinas infernales, con esos horarios. Pero dígase lo que se diga, son las que al final de la semana cuentan con un ingreso, llegan a los bailes con algo que se llama capacidad de pago ¿de las bebidas, de los tacos y los caldos a la salida?, son las que en ciertos momentos del baile y la fiesta se dan el lujo de escoger con qué tipo quieren bailar, salir y seguir. Los hombres habitan esa sociedad esperando cruzar la frontera y desempeñar el papel más heroico de ganar dólares. Pero mientras eso no se logra, y no se logra con facilidad, los hombres se reúnen en los espacios públicos para tomar o jugar futbol y 
con mucha dificultad se encargan de los hijos y del hogar. Al terminar la semana son las mujeres las que tienen recursos por modestos que sean. Son ellas las que tienen el 'poder' social y eso no es fácilmente asimilable, constituye de hecho una profunda alteración de los patrones de género. Los medios de información y la frecuencia de los asesinatos le confiere a esta agresión de género una cierta 'normalidad' en el ambiente cotidiano (en términos sociológicos a eso se llama una 'moda' y tal consideración abre un espacio para la impunidad: 'si otros matan mujeres, el que yo lo haga no puede ser tan grave')”.

\section{La reconstrucción social y las ciencias sociales y humanas}

De manera crítica y propositiva al papel de las ciencias sociales, y en particular de la sociología, Sergio dice que "si de verdad nos preocupan nuestras sociedades, entonces los temas del sufrimiento, la marginación, la incultura, el dolor de no entender el entorno en el que se vive y el caer en la violencia o en la amargura, en la regresión humana y la destrucción de la naturaleza, debieran colocarse muy por encima del economicismo dominantes en torno a la competitividad, la medición y la elección racional". La sociedad informacional, la sociología global, las grandes flechas negras que muestran los intercambios mercantiles, financieros, de la ciencia y la técnica; los estudios de la modernización, del tránsito a la democracia, no son los espacios ni los procesos que debieran concentrar, casi monopólicamente, el interés de las ciencias de lo social y lo humano.

Enfatiza que la posible reconstrucción social no va necesariamente en el sentido evolucionista de mayor técnica, mayor competitividad, de mayores intercambios exteriores, siguiendo las formas más espectaculares de la sociedad de la información y de los medios masivos, sino que comienza a construirse cada vez más a distancia de estos referentes, sirviéndose de ellos pero condicionadamente. La reconstrucción social, afirma, depende de la generación de colectivos sociales en espacios intermedios, entornos manejables para los seres sociales no profesionalizados: la autonomía regional, la democracia parti-

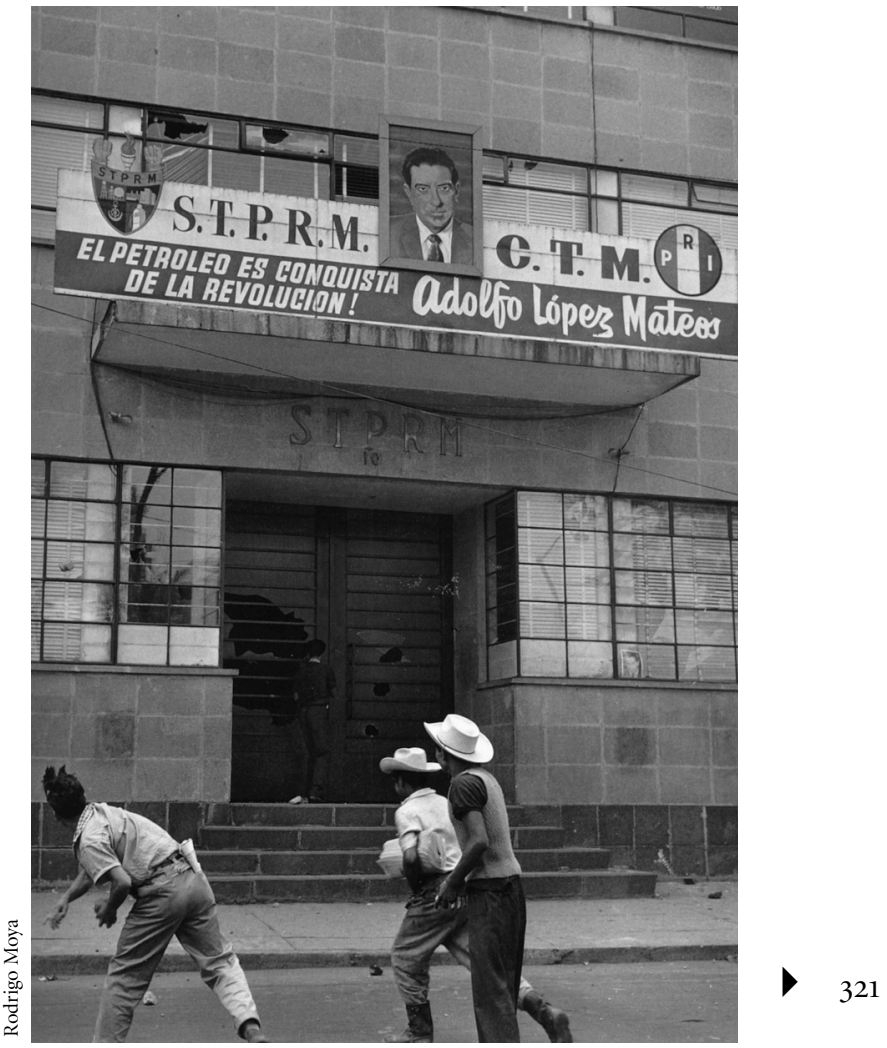

Edificio del sindicato de Pemex, ciudad de México, 1958.

cipativa, la organización vecinal, los colectivos empoderados en el plano social, capaces de entablar relaciones de respeto e igualdad con las fuerzas exteriores.

Sergio presenta una propuesta con puntos específicos para poner en práctica los procesos de empoderamiento en espacios intermedios de entre 20 y 60 mil habitantes:

- Plantear el tema de la generación-retención de riqueza material.

- Generación-retención de agentes internos organizando y dinamizando las potencialidades.

- Buscar los agentes externos (de apoyo) capaces de generar tecnologías, prácticas, formas de organización en cada campo.

- Conservar y mejorar el entorno ambiental.

- Mejorar el balance entre el poder político y el social, y entre el económico y el social. 
- La igualación de oportunidades para todos vía gasto público, los impuestos, la educación.

- Reforzamiento de una cultura cívica.

Todo ello debería conducir hacia una ética que evite las fugas de riqueza y de energía del campo social.

Habría que leer el libro para ver completa esta idea, fundamentada en seis propuestas de desarrollo y organización que se han llevado a la práctica, con distintos resultados, en España, Italia, Francia, Mississippi, Los Tuxtlas, Veracruz, Chiapas (el proyecto zapatista de Los Caracoles y las Juntas de Buen Gobierno, y otros proyectos autonomistas no zapatistas) y los Proyectos de Desarrollo Regional Sustentable de la Semarnat a partir de 1996.

\section{México: una cultura estatal. La densidad social en la historia de Occidente}

Quiero detenerme un poco más en este capítulo porque considero que es aquí donde se encuentran las razones de Sergio para explicar lo que llama "la cultura estatal", y las formas como ésta se fue desarrollando y consolidando en nuestra sociedad a través de los años y en el largo e inacabado proceso de modernización económica, social, cultural y política. En términos históricos, Sergio abarca desde el siglo XVIII, el liberalismo y la República restaurada, el porfirismo y su grupo de Científicos, los cuatro decenios de industrialización pos Revolución mexicana e impulsados por la Segunda Guerra Mundial y su cancelación con la crisis de 1982, la década perdida, las políticas neoliberales y el libre comercio. Para todo este enorme trecho histórico Sergio sostiene que se ha dado una derrota cíclica de la sociedad. Los mexicanos, dice, por lograr la modernización nos alejamos hoy, una vez más, del ideal de modernidad al que de hecho nunca hemos pertenecido.

Aquí me da la impresión de que en la definición de modernidad aún sigue predominando una visión eurocéntrica y/o anglosajona. Considero que en la sociedad mexicana actual se localizan varios sectores o nichos sociales modernos, independientemente de que esto tenga que ver con las instituciones democráticas que existen en nuestro sistema político. Creo que los mexicanos del siglo XXI estamos siendo modernos a nuestro modo, a nuestro estilo. Somos tan modernos que las instituciones del sistema político vigentes nos quedan chicas y las prácticas políticas que éste promueve nos parecen francamente detestables. Esta modernidad es la que nos está permitiendo, si bien tardíamente, que reconozcamos las culturas, tradiciones, usos y costumbres de nuestros pueblos indios y que aceptemos lo mucho que podemos aprender de ellos.

Sergio tiene razón cuando afirma que México hizo la diferencia respecto de América Latina, al darle centralidad al Estado en el proceso de construcción del proyecto de nación, por encima de la sociedad y de los cánones de la democracia liberal y la vida republicana. Lo que importaba era construir un Estado fuerte, que fuera reconocido por todas las clases sociales y aceptado como árbitro del conflicto social.

Este proceso inició desde la sangrienta guerra de Independencia y no terminó hasta entrados los años de la década de 1960, con el sistema autoritario que todos conocemos. Desde entonces "el esquema de solución a los movimientos y luchas sociales fue el siguiente: a) represión a toda forma de acción opuesta al sistema, sobre todo si se trata de un abierto enfrentamiento y una ruptura del orden; b) cooptación o muerte, o cualquier forma de desmantelamiento de sus dirigencias; y c) solución a sus demandas y reincorporación en el seno del orden imperante de lo que quedó de la dirigencia opositora, pero principalmente de las banderas de la causa.

Podríamos decir que este esquema funcionó también porque la lucha social y política de la oposición se planteaba en términos de disputa del poder y tratando de utilizar a su favor los mecanismos que el propio sistema permitía o autorizaba o a lo que los orillaba: la vía electoral constitucional o la vía revolucionaria armada y violenta. En efecto, se caía fácilmente, y se sigue haciendo, en la lógica de la cultura estatal, la lógica de la guerra, de la destrucción, de generar hombres y líderes fuertes y carismáticos con una gran capacidad de manejo de masas. Es decir, una lógica y una dinámica de lucha social que no permiten generar comunidad, o densificación social, que no permiten la creatividad para el fortalecimiento de la 
sociedad civil; o sí, pero sólo en la medida que sea para participar en los procesos electorales a sabiendas y acuerdo de que quien resulte triunfador no atentará contra el sistema. Si los procesos electorales sirvieran para transformar el sistema ya los hubieran prohibido, dijo hace algunos meses el ex diputado perredista Marco Rascón.

El Estado fuerte en México, en efecto, normaba todo y no había mucha oportunidad de escaparse de esa lógica. La lucha social y política se definía a partir de los emplazamientos estatales. Es decir, las luchas sociales se desarrollaban o dirimían en la "cancha" del Estado utilizando, como dije, sus métodos y estrategias. Por ello normalmente se perdía, o cuando se lograba ganar el triunfo costaba muchísimo (recursos, vidas) y el gusto duraba muy poco porque se terminaba cayendo en la lógica del poder.

De acuerdo, de 1968 a la fecha hemos visto cambios importantes, pero yo diría que paradójicamente también estamos viendo retrocesos, lo cual demuestra que los cambios no siempre son hacia delante. El cambio también puede ser regresivo. Sí, los partidos políticos se han fortalecido y se convirtieron en agentes importantísimos en la vida política institucional. Sin embargo, en paralelo están viviendo su peor crisis de credibilidad. De hecho, está en cuestión su capacidad de seguir siendo considerados como instrumentos de interés público o como organismos representantes de la sociedad. La alternancia en el poder se ha quedado trunca porque no ha logrado modificar la cultura estatalista heredada por el Partido Revolucionario Institucional (PRI).

Es interesante la disección y el seguimiento pormenorizado que Sergio hace de la izquierda a partir de 1968 y prácticamente hasta el surgimiento del EZLN. La agrupa en cuatro denominaciones, en función de lo que él considera era su concepción acerca de la democracia: democracia libertaria, democracia parlamentaria, democracia revolucionaria y democracia social. Todo ello como producto del movimiento de 1968.

En términos generales me parece bien esta clasificación, pero habría que establecer algunos puntos o vasos comunicantes, al menos entre las tendencias denominadas como democracia revolucionaria y democracia social. El entramado es muy complejo e imposible de ver

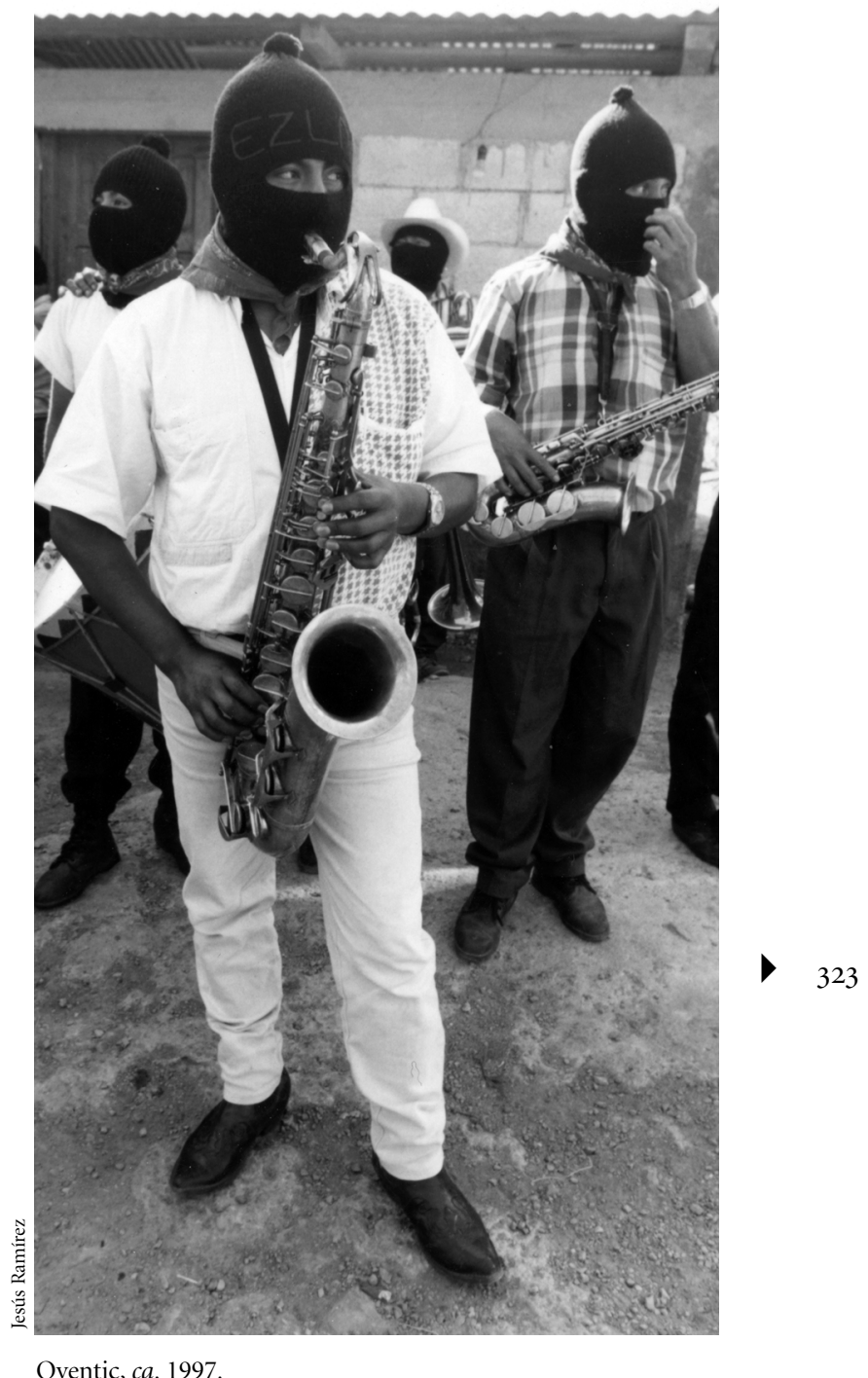

Oventic, ca. 1997.

si no se estuvo dentro. Por ejemplo, el surgimiento de las llamadas Coordinadoras de Masas (Conamup, CNPA, CNTE) es en mucho el resultado de un acuerdo entre dos conjuntos de agrupaciones de la izquierda llamada revolucionaria: la Coordinadora Línea de Masas (COLIMA) y la Coordinadora Revolucionaria Nacional (CRN). De hecho, estos dos grandes conjuntos de agrupaciones estuvieron a punto de culminar un proceso de fusión que hubiera dado como resultado un partido que no se llamaría partido y mucho menos participaría en elecciones, 
pero que sí estaría en la lógica de construir una vanguardia que condujera y diera sentido político a la lucha social. Eran múltiples y frecuentes los vínculos entre estas tendencias y los restos de la guerrilla urbana. Todo este proceso quedó trunco en el momento en que apareció el neocardenismo en 1987. Luego la construcción del Partido de la Revolución Democrática (PRD) y el Partido del Trabajo (PT) hicieron todo un desastre porque cooptaron prácticamente a todas las dirigencias sociales y las metieron, rápidamente, en la lógica de la burocracia partidaria profesional.

La matriz autoritaria del sistema político mexicano, en efecto, es una variable explicativa de los obstáculos para consolidar la organización social. Uno de los casos más dramáticos de este autoritarismo y aislamiento político en que se colocaba a cualquier movimiento o actor social activo fue el caso de la guerrilla urbana de la década de 1960. El Estado mexicano utilizó todos sus recursos legales y extralegales para exterminarlos. La democracia mexicana ha costado muchas vidas en función de este autoritarismo. Del combate a las guerrillas urbana y rural de la década de 1960 quedó una lista de más de 500 mexicanos desaparecidos e igual número de familias destrozadas y metidas en un drama político que aún no termina. Una buena parte de ellos ni siquiera eran combatientes. Tuvieron que vivir la pesadilla de la tortura y seguramente la muerte por el simple hecho de ser familiar, amigo o vecino de un guerrillero. Por ello se habla de guerra sucia.

El origen de la lucha por la defensa y promoción de los derechos humanos se encuentra en lo que en aquel entonces se denominaba como la lucha contra la represión. Más adelante, ya hacia finales de la década de 1980, del concepto pueblo se pasó al de sociedad civil y ciudadanía, y de la participación política basada en valores, principios políticos e ideológicos y sacrificio personal, se pasó a hacer de la participación política una profesión y una forma de vida. Se olvidaron los principios y los valores y se impuso el oportunismo y el cinismo político.

Me parece que tanto en la parte final de este capítulo como en las conclusiones existen algunos puntos que pudieran ser convergentes con lo que está planteado en la Sexta Declaración de la Selva Lacandona, sobre todo con respecto de la importancia de la reconstrucción social desde una lógica alejada de la cultura estatal y del poder fascinante que éste ejerce. La diferencia, me parece, es que Sergio aún le da importancia o centralidad a los partidos políticos y a la lucha por el poder público, siempre y cuando se propongan instaurar gobiernos con sentido social. Lo que propone, junto con otras voces, es una suerte de conjunción o doble uso de la fuerza social condensada: que se utilice para resolver sus demandas y para afirmarse como fuerza social autónoma, pero que a la par participe en la elección de los gobernantes. Sin oponerse como antes, sin llamar a la abstención (que ni falta hace), la otra idea es que todos los esfuerzos se centren en la reconstrucción social y que no se distraigan en otros procesos que poseen una lógica distinta porque, además, nadie puede asegurar que efectivamente un cambio de élite vendrá a resolver los problemas sociales. El trauma foxista y los casos de los presidentes de izquierda del cono sur latinoamericano, que no son pocos, indican y abonan en sentido contrario. No es que uno sea mal pensado y esté prejuiciado con los partidos, los políticos profesionales y los gobernantes. Ellos son los que se han pasado engañando a las mayorías sociales.

Finalmente, Sergio tiene mucha razón cuando afirma que la "guerrilla" zapatista nos ha enseñando que no es a través de la acumulación de fuerzas, de la epopeya milenarista, de la confrontación y del regreso a la lógica del suicida y el asesino cómo se logrará el objetivo de mejorar la calidad de vida de los pueblos indios y del resto de los mexicanos. Dice que los zapatistas tienen que demostrar a todo el mundo y a los mexicanos que sí hay un camino para superar las condiciones de opresión y de explotación, incluso en el marco de la globalidad.

Me parece muy importante que se le pida al EZLN que resuelva este tipo de retos magníficos. Ello supone que se le reconoce capacidad para hacerlo o de al menos para intentarlo. No se les pide lo mismo, ni de chiste, a los partidos políticos. El punto es que, con la Sexta Declaración, el EZLN revira este planteamiento o exigencia y llama a la sociedad para que les diga lo que piensan sobre cómo resolver el mismo acertijo.

Noviembre de 2005 